\title{
Developmental Analysis of Hippocampal Mossy Fiber Outgrowth in a Mutant Mouse with Inherited Spike-Wave Seizures
}

\author{
Xiaoxi Qiao and Jeffrey L. Noebels \\ Developmental Neurogenetics Laboratory, Department of Neurology, Section of Neurophysiology, Division of \\ Neuroscience, and Institute of Molecular Genetics, Baylor College of Medicine, Houston, Texas 77030
}

\begin{abstract}
Neural firing patterns are an essential determinant of normal axon terminal growth and synaptic connectivity in developing afferent pathways, but the trophic role of synchronous activity in associative neural networks is less well defined. We examined the ontogeny of inherited synchronous hippocampal network discharges and mossy fiber innervation patterns at sequentlal stages of development in the stargazer (stg) mutant, a single-locus mouse mutation expressing generalized spike-wave epilepsy. Brief bursts of $6 / \mathrm{sec}$ repetitive discharges arise spontaneously on postnatal days 17-18 and persistently activate neocortical and hippocampal networks throughout adulthood. We found a striking pattern of mossy fiber recurrent axon collateral sprouting in the inner molecular layer of dentate gyrus in the adult stg hippocampus. Sprouting is not apparent until 4-6 weeks following seizure onset, but then steadily intensifies with continued synchronous activation. In the adult mutant, axon outgrowth is accompanied by a mild selective loss of hilar interneurons without gliosis. These data indicate that hypersynchronous stimulation during late postnatal brain development is linked, following a prolonged latent period, to significant fiber outgrowth and synaptic reorganization within the hippocampal formation. Since the pattern of synchronous activation in the stg mutant strongly resembles that seen in human spike-wave absence epilepsy, the synaptic plasticity described in this model has important implications for normal brain development in this common disorder.
\end{abstract}

[Key words: synaptic plasticity, sprouting, synchronous firing patterns, cell death, zinc]

Activity-dependent plasticity of synaptic connections has been demonstrated in the terminal projections of primary sensory pathways in the mammalian CNS (Wiesel and Hubel, 1963; Archer et al., 1982; Shaw and Cynader, 1984; Stryker and Harris, 1986; Shatz and Stryker, 1988) and plays a key role in Hebbian models of brain development (reviewed by Constantine-Paton, 1990; Shatz, 1990). While most experimental paradigms have involved the prolonged reduction of nervous im-

\footnotetext{
Received Jan. 27, 1993; revised May 19, 1993; accepted May 24, 1993.

We thank Bernadette Powell for assistance with the electron microscopy. This work was supported by NS 29709 (NIH), HD 24064 (NICHD), the Pew Biomedical Scholars Program, and the Blue Bird Circle Foundation for Pediatric Neurology.

Correspondence should be addressed to Jeffrey L. Noebels, M.D., Ph.D., Department of Neurology, Baylor College of Medicine, One Baylor Plaza, Houston. TX 77030.

Copyright (C) 1993 Society for Neuroscience $0270-6474 / 93 / 134622-14 \$ 05.00 / 0$
}

pulse activity following sensory deprivation or pharmacological blockade, sustained increases in impulse activity can also alter the organization of developing synaptic circuits (Chow et al., 1978; Baumbach and Chow, 1981). The neural firing pattern and level of postsynaptic coactivation, in addition to the absolute amount of impulse traffic, are important determinants of synaptic stabilization (Hubel and Wiesel, 1965; Mastronarde, 1983; Sretavan and Shatz, 1986). Together, these studies have demonstrated a clear overall dependence of synaptogenesis in afferent pathways on temporally correlated neuronal spike activity, and illustrate the importance of epigenetic factors in refining functional connectivity within the developing brain.

The plasticity observed during the selection and innervation of postsynaptic targets in sensory pathways declines after a critical period in development, but various lines of evidence suggest that impulsc activity continues to influence the stability of axon terminal connections during adulthood. Selective elimination of one afferent input pathway can result in the sprouting of uninjured neighboring terminals in mature animals (Lynch et al., 1973; Zimmer, 1974; Laurberg and Zimmer, 1981; Merzenich et al., 1983). Extensive synaptic reorganization also occurs in the adult in associative neural networks such as the dentate gyrus granule cell-mossy fiber system following excessive synchronous activity in several models of hippocampal seizures (Nadler et al., 1980; Sutula et al., 1988; Babb et al., 1991), and in human temporal lobe epilepsy (Sutula et al., 1989; Houser et al., 1990). While the mechanisms triggering axon growth following seizures are clearly associated with neural network hyperactivity, the synchronous discharges in each of these models are also accompanied by extensive neuronal cell death, synaptic loss, and gliosis (Nadler et al., 1980; DeLanerolle et al., 1989; Cavazos and Sutula, 1990; Houser et al., 1990), and the relative contributions of each of these linked phenomena have not yet been well defined.

We recently described a new recessive neurological mutant locus, stargazer (stg, Chr 15) with a highly stereotyped pattern of generalized absence seizures resembling petit mal epilepsy (Noebels et al., 1990). Each cortical EEG discharge consists of a tetanic burst of spike-waves in the theta frequency range (6/ sec) lasting 1-10 sec and occurring at a mean rate of $1-2 / \mathrm{min}$. While the primary mechanism underlying these oscillations is believed to be an enhancement of endogenous membrane burst firing properties centered in the reticulothalamocortical circuit (Steriade et al., 1990), other synaptically linked brain regions in the stg mutant, in particular the hippocampus, also participate as secondary targets of the hypersynchronous activity. The brief episode of phasic neural firing during a nonconvulsive spike- 
wave oscillation differs from the prolonged pattern of tonic bursting observed in convulsive seizures in several distinctive ways, most notably by the absence of postictal EEG depression, a deleterious phenomenon that consists of an immediate flattening of brain wave activity due to a massive depression of postsynaptic potentials in the cortical neuropil. This period of profound depolarization reflects the recovery from excessive release of excitatory neurotransmitters, extracellular accumulation of potassium ions, neuronal metabolic energy depletion, and increased entry of intracellular calcium ions, predisposing the circuit to excitotoxic cell death. In contrast, EEG activity following a spike-wave discharge is unaltered, suggesting that this specific pattern of synchronization activates the circuit within the margins of normal intracellular metabolic demands.

In the present study, we sought to determine whether this spontaneous pattern of endogenous network hypersynchrony could serve as a sufficient stimulus to alter hippocampal connectivity by examining adult stargazer mutant mice for evidence of recurrent mossy fiber axon collateral growth and signs of associated cell death. We ascertained the exact developmental onset of the synchronous activity, correlated the subsequent temporal pattern of the discharges with the growth and ectopic distribution of dentate granule cell axon terminals, quantified regional cell loss, and looked for a functional role, based on the sequence of their appearance, these phenomena might play in mechanisms underlying axonal sprouting and the inherited spikewave epilepsy phenotype.

\section{Materials and Methods}

Animals. Adult $+/+\mathrm{C} 57 \mathrm{BL} / 6 \mathrm{~J}$, and $s t g / s t g \mathrm{C} 3 \mathrm{~B} 6 \mathrm{Fe}+$ mice from breeding colonics of the Jackson Laboratory and Baylor College of Medicine were kept on a $12 \mathrm{hr}: 12 \mathrm{hr}$ light/dark cycle with food and water available ad libitum. Heterozygous males $(+/ s t g)$ and homozygous females $(s t g /$ $s t g$ ) were mated to produce $s t g / s t g$ mice. Homozygotes could be distinguished from heterozygous littermates as early as 2 weeks postnatal by their reduced body size and mild ataxia.

Chronic EEG recordings. Mice 2 weeks of age and older were anesthetized with Avertin (1.25\% tribromoethanol/amyl alcohol solution) by intraperitoneal injection $(0.02 \mathrm{ml} / \mathrm{gm})$. Silver wire electrodes $(0.005$ inch diameter) soldered to a microminiature connector were implanted bilaterally into the subdural space over frontal and parietal cortices. Electroencephalographic (EEG) activity was recorded daily during random 1-2 hr samples for 2-7 d using a Grass model 6 electroencephalograph. All recordings were carried out at least $24 \mathrm{hr}$ after surgery on micc moving frecly in the test cage. EEG traces were reviewed for the incidence and duration of spontaneous cortical spike activity. Discharges with a minimum amplitude of twice the background EEG voltage and minimum duration of $1 \mathrm{sec}$ were considered for analysis, and spike bursts separated by less than $1 \mathrm{sec}$ were counted as a single discharge.

Stereotaxic surgery was performed in some mice to implant a twisted pair of Teflon-sheathed depth electrodes in the dorsal hippocampus. Under Avertin anesthesia, mice were mounted in a stereotaxic frame and the cranial sutures exposed. The points of bregma, lambda, and the auditory meatus were used for reference. A correction factor for the stereotaxic coordinates for mouse brain was calculated according to the regression equation $F^{\prime}=F_{a}-0.66(b l-3.8)$, where $F^{\prime}$ is the predicted frontal coordinate of a particular neural point, $F_{a}$ is the frontal coordinate of that point given by a mouse brain atlas (Slotnick and Leonard, $1975), \quad 0.66$ is the mean regression coefficient determined from the variability study, and $b l$ is the bregma-lambda distance of the mouse The anterior, lateral, and depth hippocampal coordinates used in adult mutants were AP $-2.0 \mathrm{~mm}$, L $2.0 \mathrm{~mm}$, and D $1.6 \mathrm{~mm}$.

Zinc histochemistry: Timm's and selenium stain. The Timm's stain method used was modified from Haug (1973). Mice were anesthetized with Avertin and killed by transcardial perfusion with sodium sulfide solution $\left(1.2 \% \mathrm{Na}_{2} \mathrm{~S}\right.$ in $0.15 \mathrm{M}$ phosphate buffer, $\left.\mathrm{pH} 7.4\right)$ at $25^{\circ} \mathrm{C}$ for 20 $\mathrm{min}$. The brain was excised and frozen in $\mathrm{CO}$, vapor. Coronal, sagittal, and horizontal sections were cut in a cryostat at $20 \mu \mathrm{m}$. The sections were fixed in $96 \%$ ethanol for 15 min, hydrated through an alcohol series, and stained in an aqueous solution consisting of $60 \mathrm{ml}$ of $50 \%$ w/v gum arabic, $10 \mathrm{ml}$ of sodium citrate buffer, $30 \mathrm{ml}$ of $5.7 \%$ hydroquinone, and $0.5 \mathrm{ml}$ of $17 \%$ silver nitrate for physical development. Slides were maintained in a dark box at $26^{\circ} \mathrm{C}$ for $40-60 \mathrm{~min}$, and rinsed in tap water for $5 \mathrm{~min}$ after development. The sections were then dehydrated in graded ethanol, cleared briefly in xylene, and coverslipped with Permount.

An alternative zinc histochemical staining method, selenium stain, was modified from Danscher (Danscher, 1982) to examine mossy fiber trajectories further. Sodium selenite $\left(\mathrm{Na}_{2} \mathrm{SeO}_{3}\right)$ was injected intraperitoneally $(15 \mathrm{mg} / \mathrm{kg})$, and the animals were anesthetized $1 \mathrm{hr}$ later and perfused transcardially with $0.9 \% \mathrm{NaCl}$. The brain was removed and frozen with $\mathrm{CO}_{2}$. Horizontal sections were cut in a cryostat at $20 \mu \mathrm{m}$ thickness. Dried sections were fixed in $100 \%$ ethanol at room temperature for $15 \mathrm{~min}$. The slides were hydrated in graded ethanol and coated with $0.5 \%$ gelatin prior to physical development. The development was carried out in a solution of $50 \%$ gum arabic $(60 \mathrm{ml})$, sodium citrate buffer $(10 \mathrm{ml}), 5.7 \%$ hydroquinone $(15 \mathrm{ml})$, and $15 \mathrm{ml}$ of $0.8 \%$ silver lactate in a dark box at $26^{\circ} \mathrm{C}$ for $60-70 \mathrm{~min}$. The slides were then rinsed in running tap water at $40^{\circ} \mathrm{C}$ for $45 \mathrm{~min}$, bathed in $5 \%$ sodium thiosulfate for $12 \mathrm{~min}$, dehydrated in graded ethanol, cleared in xylene, and coverslipped with Permount.

Brain sections stained for the presence of vesicular zinc with both Timm's and selenium methods were used to ascertain the extent of recurrent mossy fiber outgrowth. In preliminary studies at sequential levels through the septal-temporal axis, we determined that the mossy fiber sprouting in the dentate was most pronounced in the temporal pole of the hippocampus, and therefore concentrated on this region for the image analysis of staining density, localization of zinc-containing mossy fibers in Timm's stained electron microscopic sections, and the developmental study of sprouting. Age-matched sections from each genotype were processed simultaneously on the same slide rack to permit accurate histochemical comparisons between groups. Sections of each brain at the midtemporal hippocampus, the level where the dentate gyrus in horizontal brain sections turns from a U-shape to a V-shape (about $3 \mathrm{~mm}$ from dorsal surface; horizontal sections 131-155 in Sidman et al., 1971), were assigned a standard score from 0 to 3 related to the density of inner molecular and granular mossy fiber staining (Tauck and Nadler, 1985). Sections with no, or occasional, molecular or granular mossy fiber staining were scored 0 . Sections with scattered mossy fiber staining in the inner molecular layer (IML) were given a score of 1. Obvious dark staining forming a distinct band in the IML was scored as 2 , and sections with a dense, continuous band of black staining in both IML and granular layer were scored 3.

Regional densitometry. A computer-assisted image analysis system (RAS-DG3000, Loats Associates) was used to quantitate the relative optical density measurements of regional staining patterns and specific neuronal populations in the hippocampus. Mean optical density was measured from three different regions of the Timm's stained horizontal sections of temporal hippocampus in six adult $+/+$ and $\mathrm{stg} / \mathrm{stg}$ mice at matching levels along the temporoseptal axis. Regions selected were the dentate hilus (area within the suprapyramidal and infrapyramidal blades of the dentate granule cell layer), and the entire inner molecular and granular cell body layers of the dentate, using the stratum lacunosummoleculare as an internal standard for comparison of background staining levels. Since the exact demarcation between the molecular layer and adjacent granule cell body layers in digitized Timm's stained sections was usually indistinct, the two layers were combined for more accurate mean optical density measurements. The analog video signal was corrected for background illumination and digitized so that the optical density of each $3 \times 3 \mu \mathrm{m}$ area of the section, corresponding to one pixel, represented a value from 0 to 225 . The specific staining density in each section was standardized across slides by subtracting the nonspecific background density value in the stratum lacunosum-moleculare from the density value in the hilar and molecular-granular regions. Differences in the density between genotypes in identical regions were analyzed for statistical significance by two tailed Student's $t$ tests. Area measurements of the granular cell body layer and CA3 pyramidal cell layer in 18-22 temporal hippocampal sections from each of three control and three mutant stg mice were performed on cresyl violet-stained sections. The Student $t$ test was used to compare the significance levels between the mean areas in the two genotypes.

Electron microscopy of Timm's stained hippocampus. The Neo-Timm's stain method was used for ultrastructural localization of zinc-rich axon terminals (Danscher, 1981). Mice 4-5 months old were anesthetized 
with Avertin and perfused transcardially with $0.1 \% \mathrm{Na}_{2} \mathrm{~S}$ and $3 \%$ glutaraldehyde in Sorensen buffer. The hippocampus was dissected and placed in the glutaraldehyde solution for $1 \mathrm{hr}$. Thick sections $(100 \mu \mathrm{m})$ were cut on a vibratome, rinsed with phosphate buffer, and stained in the Timm's stain developing solution for $70 \mathrm{~min}$ in a dark box at $26^{\circ} \mathrm{C}$ with constant stirring. After a rinse in $0.1 \mathrm{M}$ Sorensen phosphate buffer, the sections were postfixed in $1 \% \mathrm{OsO}_{4}$ in $0.1 \mathrm{M}$ phosphate buffer for 1 $\mathrm{hr}$ before embedding in Epon. Ultrathin sections were cut from polymerized Epon blocks, counterstained with $2 \%$ uranyl acetate and lead citrate, mounted on grids, and examined with a JEOL JEM-1200 EX II electron microscope.

Neuron counts. Cresyl violet-stained horizontal frozen brain sections (16 $\mu \mathrm{m}$ thickness) prepared from three pairs of 5-month-old $+/+$ and stg/stg mice and two pairs of postnatal day $17(\mathrm{P} 17)+/+$ and $s t g / s t g$ mice were examined to determine the morphological characteristics of the three hippocampal regions. Ten horizontal sections across the temporal pole of the hippocampus were used for neuron counting in each mouse. Three cell populations, including granule cells, CA3 pyramidal cells, and hilar polymorphic cells in the adult group, and one population, hilar cells, in the immature group were counted using a Zeiss Videoplan image processor interfaced with a light microscope through a Panasonic video camera. A $100 \times$ oil immersion objective lens focused on a circular area of $3481 \mu \mathrm{m}^{2}$ was used for neuronal counting. Three discrete areas from the crest and the supra- and infrapyramidal limbs of the dentate gyrus were used to determine granule cell number, the corresponding hilar regions beneath the crest and both limbs of dentate were used for hilar cell number, and the CA3a, -b, and -c subfields were sampled for CA3 pyramidal cell counts. The means of the three determinations were used as the raw nuclear count for each section. To correct for neuronal overlap in each field, only nuclei in contact with the upper and left borders of the sample window were counted. To avoid subjective bias, the genotype of all sections was not revealed until counting was completed.

Mean neuronal density $(N)$ for each region was calculated from the raw nuclear count $(n)$ using a correction factor: $N=n T /(T+D)$, where $T$ is the section thickness, and $D$ is the average nuclear diameter of the specific cell population (Abercrombie, 1946). To exclude systematic changes in tissue volume that alter neuronal density, the mean neuronal densities were adjusted for potential volume changes according to the formula $N_{v}=N\left(V_{m} / V_{c}\right)$, where $V_{m}$ and $V_{c}$ are the average section volumes of each region from the mutant group and the control group, respectively. The mean section volumes of granule cells and CA3 pyramidal cells in adult $+/+$ mice were used as control volume $\left(V_{c}\right)$. In hilar cells, the average section volume of P17 $+/+$ mice was used as $V_{c}$ for both adult and immature groups. The volume-corrected neuronal density of each section was then analyzed by two-tailed Student's $t$ test for significant differences between the two genotypes.

Glial fibrillary acidic protein immunocytochemistry. One pair of anesthetized $+/+$ and $s t g / s t g$ mice was perfused with $4 \%$ paraformaldehyde in $0.1 \mathrm{M}$ phosphate buffer ( $\mathrm{pH} 7.4$ ). Brains were removed, rinsed in phosphate buffer overnight, and cryoprotected in graded sucrose in 0.1 м buffer solution. Horizontal brain sections $(16 \mu \mathrm{m})$ were cut in a cryostat, mounted on subbed slides, and air dried. Sections were stained for glial fibrillary acidic protein (GFAP) using rabbit anti-bovine polyclonal antibody (Accurate Chemical and Scientific Corp.) and the immunoperoxidase method (Beltz and Burd, 1989) with avidin-biotin reagents (Vector Laboratory).

\section{Results}

\section{Comparison of Hippocampal EEG and Timm's staining} patterns in adult $+/+$ and $\mathrm{stg} / \mathrm{stg}$ mice

Typical EEG traces recorded simultaneously from frontal cortex and hippocampus of freely moving adult $+/+$ and $\mathrm{stg} / \mathrm{stg}$ mice are illustrated in Figure 1. The stg homozygote shows a highly reproducible pattern of spontaneous bilaterally symmetrical 6$7 /$ sec spike-wave discharges in both cortical and hippocampal regions. The hippocampal discharges are similar in morphology and amplitude to those in neocortex, and can be recorded with either bipolar depth electrodes $(n=3)$ or monopolar hippocampal electrodes referred to the inactive cerebellar surface $(n=2)$. Apart from the spike-wave seizures, no other abnormal activity could be recognized in chronic cortical or hippocampal record- ings. The spontaneous seizure rate in adult $s t g / s t g$ mutants ranges from 43 to 209 discharges/hr (mean of $130 / \mathrm{hr}$ ), and the seizure duration ranges from 1 to $66 \mathrm{sec}$ (mean of 4-6 sec). Patterned spike-wave synchronous discharges represent approximately $20 \%$ of total EEG activity in the adult stg mutant (Noebels et al., 1990; Qiao and Noebels, 1991).

Representative Timm's stained horizontal brain sections from the temporal hippocampus of adult $+/+$ and $s t g / s t g$ mice are shown in Figure 1. The dark Timm's-silver precipitate is present in regions corresponding to the mossy fiber terminal fields, and the innervation pattern in the wild-type mouse is essentially identical to that described in the rat (Haug, 1973; Gaarskjaer, 1978). Staining is dense in fibers traversing the hilar polymorph region and extending into the mossy fiber bundle from the $\mathrm{CA} 3$ region to the terminus at the $\mathrm{CA} 3 / \mathrm{CA} 2$ junction. No staining is present in the IML of the dentate gyrus in the $+/+$ mouse (Fig. $1 A$, arrows), while a comparable section from the stg mutant hippocampus shows a striking increase in staining along the full extent of the dentate IML (Fig. 1B). Although the absolute intensity of the staining in the molecular layer varied in different individuals, the increase was consistently observed in five of six matched pairs of adult $+/+$ and $s t g / s t g$ mice examined. Table 1 shows the corrected optical density measurements of Timm's specific staining in hippocampal sections from six matched pairs of adult $+/+$ and $s t g / s t g$ mice. Statistical analysis of these results revealed no difference in the mean optical density measurements of the hilar region in control and stargazer sections, but showed a significant mean increase of $48 \%(P<0.05)$ in Timm's stain density within the inner molecular-granular cell layer of the mutant compared to the $+/+$ brain.

A similar result was obtained employing selenium, a second histochemical staining method for zinc in the hippocampus (Fig. 2). Compared to the Timm's method, selenium-stained sections clearly revealed the abnormal staining in the IML of the mutant while displaying a lower background and a more distinct laminar structure within the dentate outer, middle, and inner molecular layers. The micrographs in Figure 2 are cross sections of the dentate gyrus at matching levels of mid- $(A-D)$ and upper-temporal $(E-H)$ hippocampus in 6-month-old $+1+(A, C, E, G)$ and $\operatorname{stg} / \operatorname{stg}(B, D, F, H)$ mice, shown at medium $(A, B, E, F)$ and high magnification $(C, D, G, H)$. Scattered staining of mossy fiber collaterals was observed in the inner molecular and granule cell body layers of the $t / t$ temporal hippocampus (Fig. $2 A, C$ ). In contrast, a thick and continuous band of intense selenium stain covered the entire IML in the corresponding levels of the mutant (Fig. $2 B, D$ ). At the medial hippocampal level (Fig. $2 E-$ $H$ ), both $+/+$ and $s t g / s t g$ mice showed less staining in the IML compared to their respective temporal regions, but the abnormal staining in stg/stg mutants still exceeded that present in $+/+$ sections. There was no IML staining within the septal region in either genotype (data not shown).

\section{Electron microscopy of $\mathrm{stg}$ mossy fiber sprouting}

In Timm's stained thin sections from the granule cell body layer (Fig. $3 A$ ) and IML (Fig. $3 B$ ) of the stg temporal hippocampus, electron micrographs revealed clustered Timm's positive particles intermixed with neurotransmitter vesicles and mitochondria within mossy fiber terminal-like elements. The morphology of these ectopic terminals was similar to, but substantially smaller than, the mossy fiber terminals found in the hilus and in the 


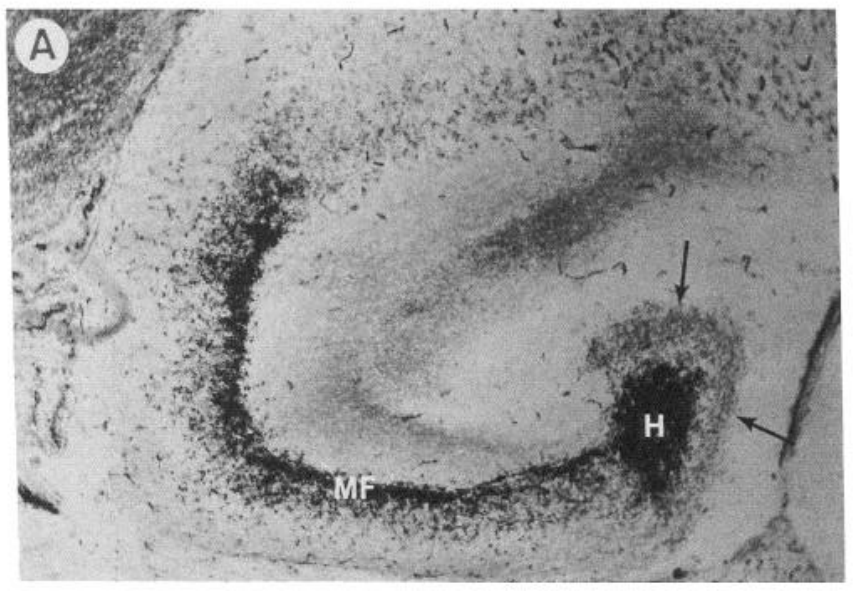

C

$\mathrm{L}$ fron ctx-cbl

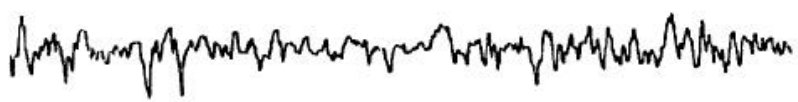

L hpc-hpc

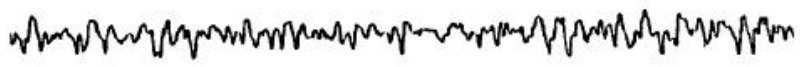

stg/stg

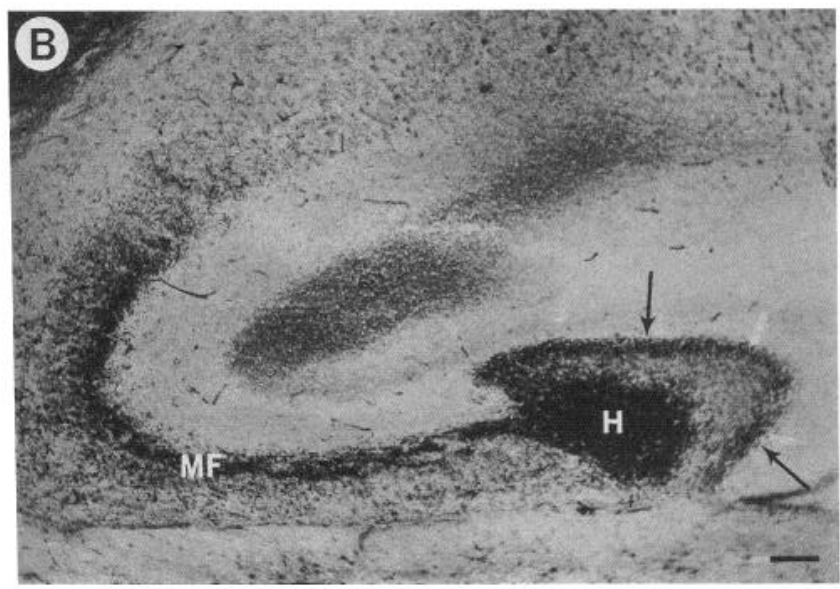

D

L fron ctx-cbl

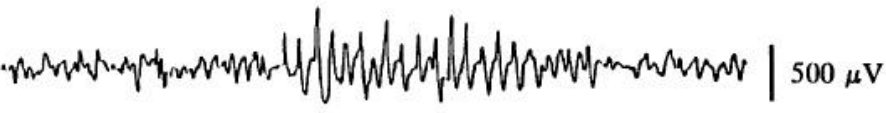

L hpc-hpc

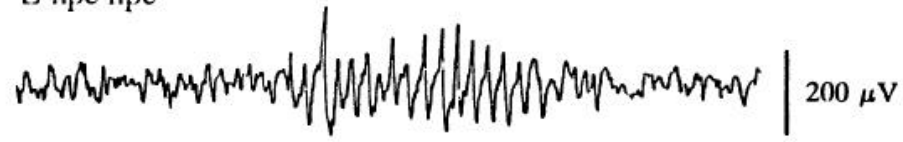

1 second

Figure 1. Hippocampal mossy fiber sprouting and spike-wave seizures in the stargazer mutant mouse. $A$ and $B$, Timm's sulfide silver-stained horizontal brain sections from the temporal hippocampus of adult $+/+(A)$ and $s t g / s t g(B)$ mice. The dark precipitate is present in regions that correspond to the mossy fiber pathway. The staining is most dense in the hilar polymorph region $(H)$, and the mossy fiber $(M F)$ bundle extending from the CA3 region to the junction of CA3-CA2. No staining is present in the IML bordering the granule cells of the dentate gyrus ( $A$, arrows) in $+/+$ mice. Comparable sections from the $s t g / s t g$ mutant hippocampus show a striking increase in Timm's stain granules in the IML (B, arrows), forming a continuous dark staining supragranular band. Scale bar, $100 \mu \mathrm{m}$. $C$ and $D$, EEG traces recorded simultaneously from left frontal cortex monopolar electrode referred to cerebellum (top trace) and from bipolar hippocampal electrode (bottom trace) in adult $+/+(C)$ and stg/stg $(D)$ mice. The stg homozygote shows spontaneous 6-7 spikes/sec spike-wave seizure discharges arising simultaneously in both cortical and hippocampal regions. No other abnormal activity patterns were present in chronic hippocampal recordings from adult mutants.

CA3 region, confirming that the aberrant Timm's staining pattern observed by light microscopy in stg hippocampus represents actual staining of mossy fiber axon terminals. Axodendritic contacts of these terminals were abundant in the mutant dentate molecular layer; however, no secondary evidence for synapse formation between zinc-containing terminals and dendrites of granule or basket cells, such as a clear postsynaptic density associated with the zone of apposition, was observed. This may be related to the limited preservation of osmium staining when combined with the sulfide silver staining technique.

Table 1. Optical density measurements of Timm specific staining in adult $+/+$ and $\mathrm{stg} / \mathrm{stg}$ hippocampus

\begin{tabular}{llllllllll}
\multicolumn{8}{c}{ Sample number } \\
\cline { 2 - 9 } & Mice & 1 & 2 & 3 & 4 & 5 & 6 & Mean \pm SE & $p$ \\
\hline Hilar region & $+/+$ & 2.03 & 2.01 & 1.64 & 1.61 & 1.61 & 2.11 & $1.84 \pm 0.24$ & \\
& stg/stg & 2.06 & 2.05 & 1.97 & 1.78 & 1.93 & 1.88 & $1.95 \pm 0.11$ & $>0.05$ \\
IML region & $+/+$ & 0.18 & 0.24 & 0.14 & 0.12 & 0.11 & 0.20 & $0.17 \pm 0.05$ & \\
& stg/stg & 0.32 & 0.24 & 0.20 & 0.15 & 0.16 & 0.40 & $0.25 \pm 0.10$ & $<0.05^{*}$ \\
\end{tabular}

* Statistically different from control data. 

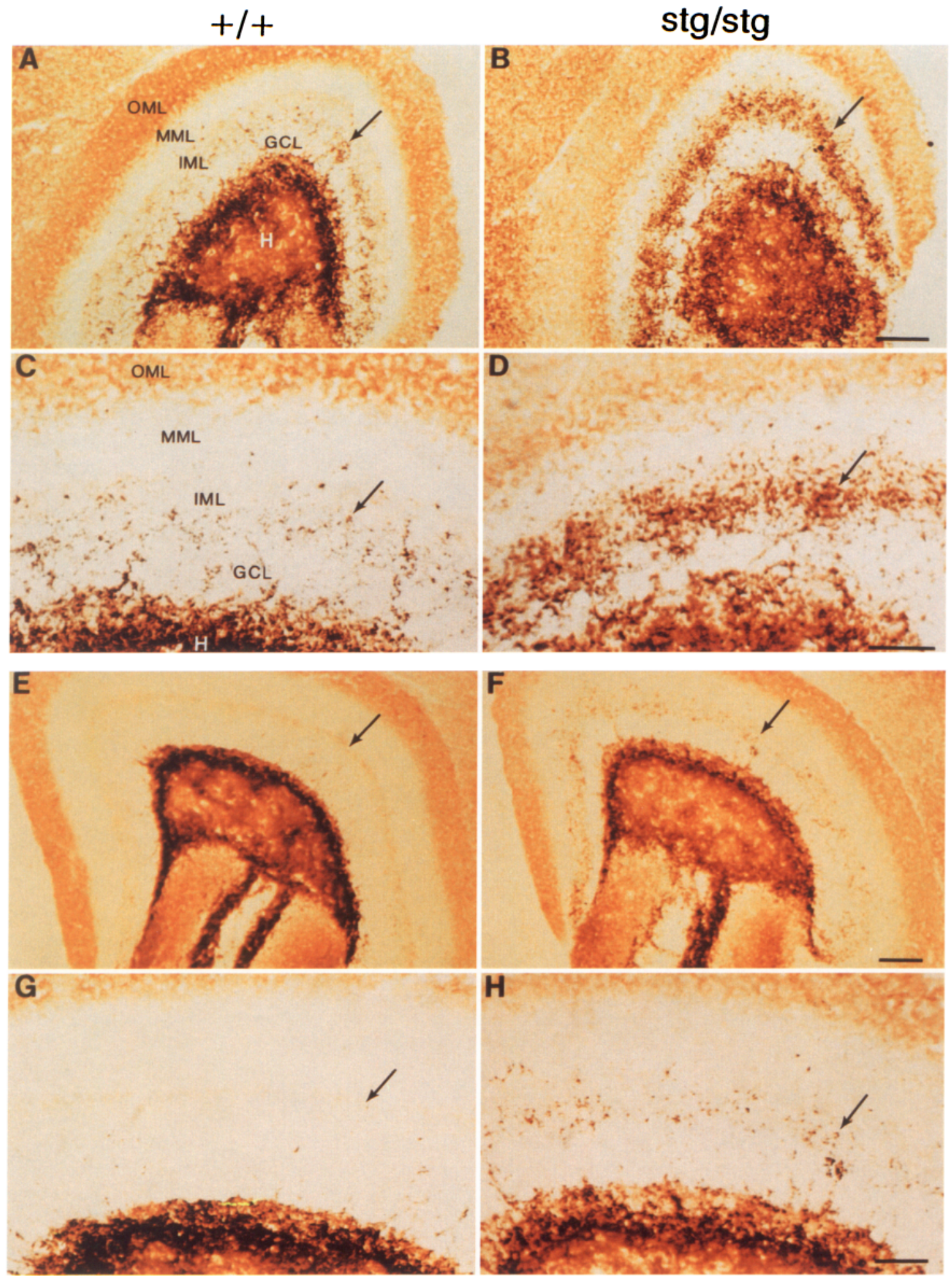

Figure 2. Comparison of the spatial distribution of mossy fiber collaterals in the IML (arrows) of selenium-stained sections of the temporal dentate gyrus in 6-month-old $+/+(A, C, E, G)$ and $s t g / s t g(B, D, F, H)$ mice. The selenium stain reveals the distinct laminar organization within the dentate molecular layer, consisting of outer, medial, and inner molecular layers $(O M L, M M L, I M L)$. There is scattered staining of mossy fiber terminals in the IML and the granule cell layer $(G C L)$ of the $+/+$ temporal hippocampus $(A$; higher magnification in $C)$. In contrast, a thick and continuous band of intense staining covers the entire IML in the corresponding levels of stg mutant $(B, D)$. At the medial hippocampal level $(E-$ $H$ ), both $+/+$ and $s t g / s t g$ have less staining in the IML compared to their temporal regions, but the staining in the mutant still exceeds that in control sections. $H$, hilus. Scale bars: $A, B, E$, and $F, 100 \mu \mathrm{m} ; C, D, G$, and $H, 50 \mu \mathrm{m}$. 

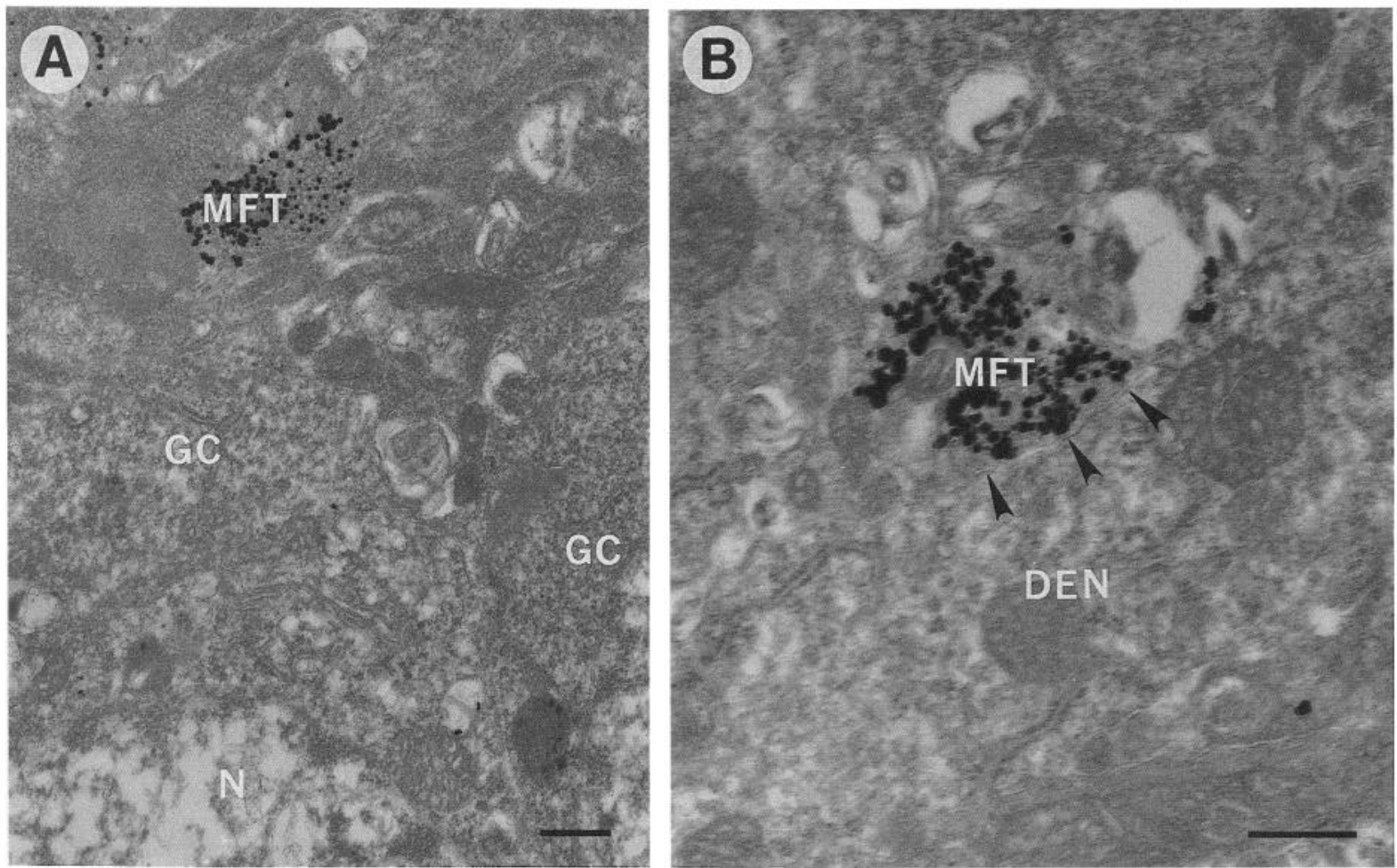

Figure 3. Timm's stained electron micrographs from the granule cell layer $(A)$ and IML $(B)$ of the stargazer dentate gyrus. Clustered Timm's positive particles are found in mossy fiber terminals $(M F T)$ intermixed with neurotransmitter vesicles and mitochondria. The zinc-containing mossy fiber terminal in $B$ is in close contact (arrowheads) with a dendrite $(D E N)$, presumably originating from a granule cell (GC). $N$, granule cell nucleus. Scale bars, $500 \mathrm{~nm}$.

\section{Development of seizure expression and mossy fiber sprouting}

Mice ranging from P14 to 6 months of age were used to study the ontogeny of seizure activity and mossy fiber sprouting. The chronological onset and mean incidence of seizure activity dur- ing development of stg mutant mice are illustrated in Figure 4. As indicated by serial EEG studies from 3-week-old stg mutants (Fig. 4A), no spike-wave discharges were ever recorded from P15 mice, but were always present by P18 $(n=4)$. With the exception of a slightly slower spike frequency $(4-5 / \mathrm{sec})$ during
A

P15 L

$R$

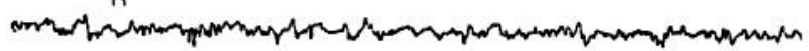

P 18

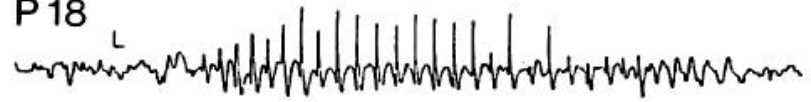

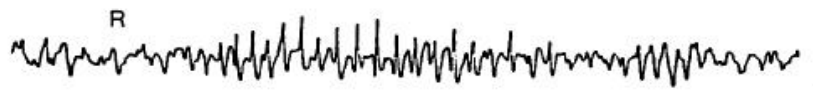

$\mid 500 \mu \mathrm{V}$

$1 \mathrm{sec}$
B

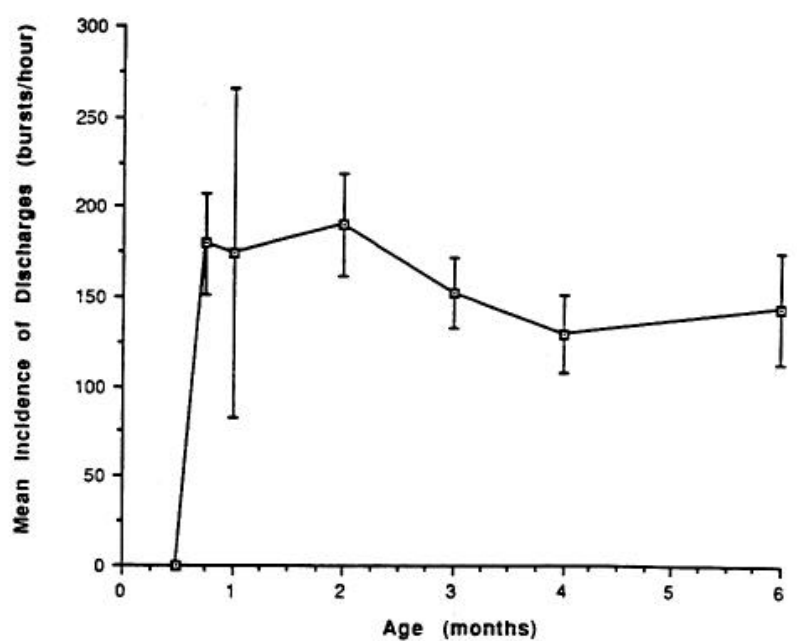

Figure 4. Onset and mean incidence of synchronous discharge activity in stargazer mutant mice during development. $A$, Representative bilateral EEG traces recorded on P15 and P18 in stg/stg mutants. No discharges were ever recorded from P15 mutants, but were always present by P18 in the $s t g / s t g$ mice $(n=4)$. Except for a slightly slower spike frequency during the burst $(4-5 / \mathrm{sec})$, the spike-wave discharges in the immature mouse brain display a similar pattern and duration to those seen in the adult. $B$, Group data showing the mean incidence of cortical discharges in stg mice at ages ranging from P15 to 6 months postnatal. Each age point includes mean data from two to eight mice \pm SE. Within 1 week of onset, the expression of spontaneous discharges maintained a steady rate of approximately $150 \mathrm{bursts} / \mathrm{hr}$. 


\section{$+1+$}

P 15

P 30

\section{2 months}

4 months

\section{6 months}
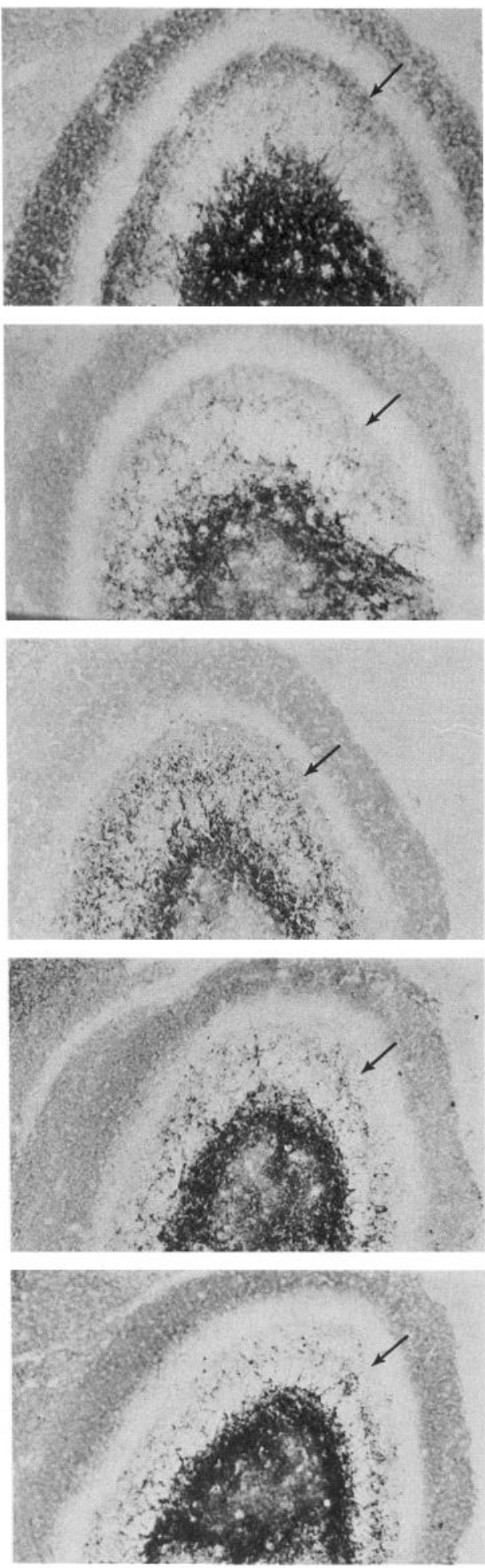

\section{stg/stg}
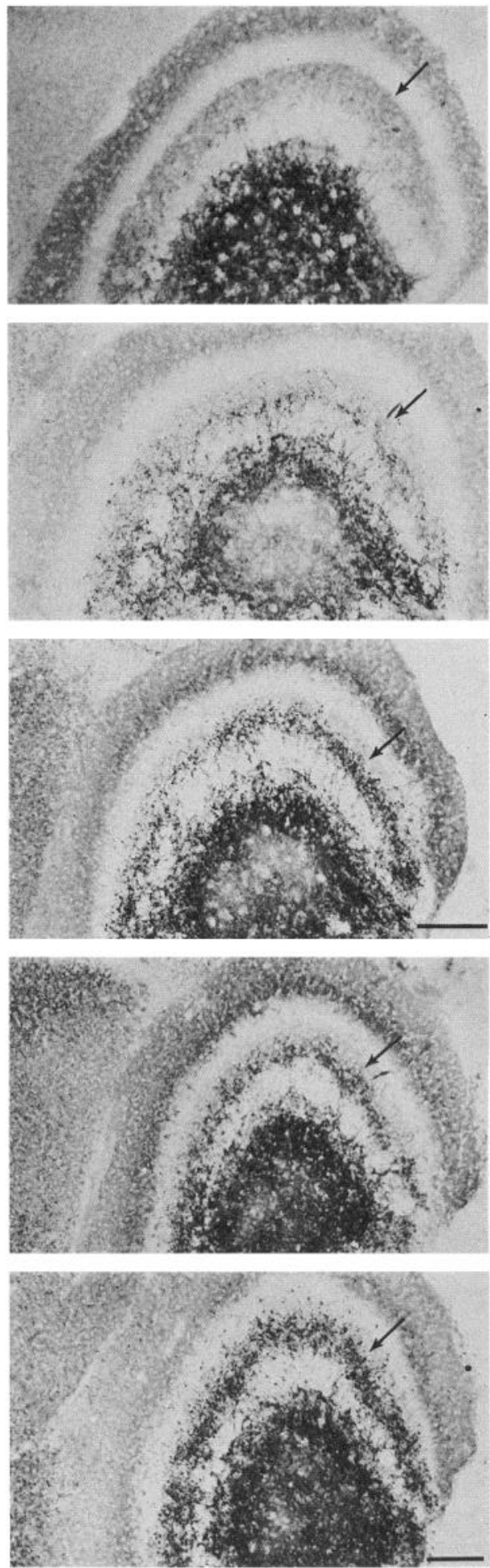

Figure 5. Developmental onset of mossy fiber sprouting visualized in selenium stained sections of the dentate gyrus from temporal hippocampus in pairs of age-matched $+1+$ and stg/stg mice. At P15, before seizure onset, no mossy fiber outgrowth could be detected in the IML (arrow) of either control or $\mathrm{stg} / \mathrm{stg}$ dentate gyrus. At $P 30,12 \mathrm{~d}$ post-seizure onset, evidence of selenium staining in the mutant IML is barely visible but not significantly different from control staining patterns. At 2 months, selenium staining in the stg IML is clearly more intense compared to control sections. At 4 months and 6 months, stg mutants show increasing selenium stain intensity in the IML and granule cell layer. Scale bars, $100 \mu \mathrm{m}$. 
A

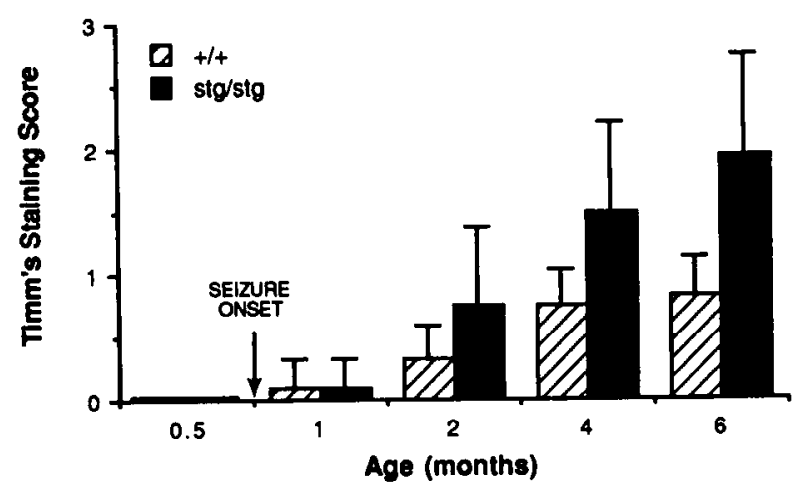

B

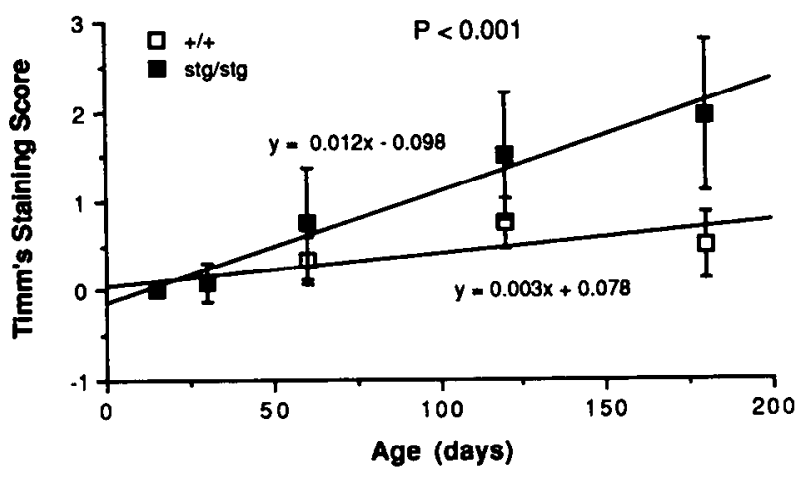

C

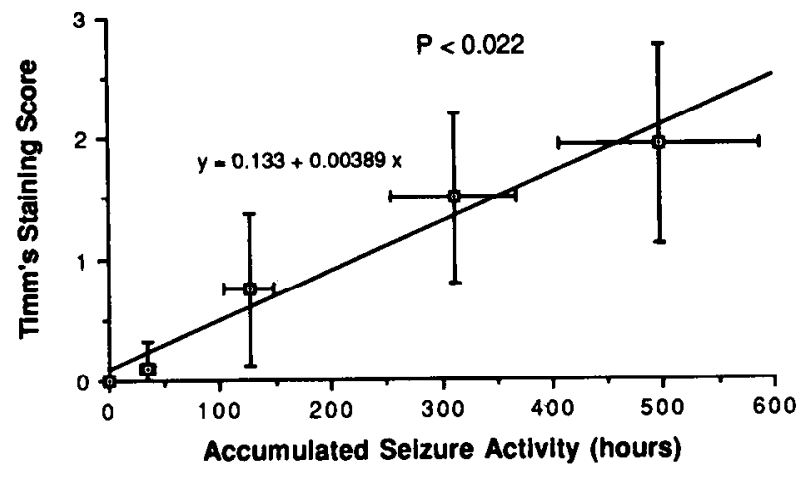

Figure 6. Correlative analysis of dentate IML Timm's staining with genolype, developmental age, and seizure history. The mean Timm's staining score $( \pm$ SE) is from midtemporal hippocampal sections in the dentate gyrus in matched groups of mice $(n=4-8)$ at different ages. Scores: 0 , no or trace IML or supragranular mossy fiber staining; 1 , scattered IML mossy fiber staining; 2, clear black staining forming a distinct band in the IML; 3 , a dense, continuous band of staining covering the IML and granular layer. $A$, Comparison of Timm's staining score from $+/+$ and $\mathrm{stg} / \mathrm{stg}$ mice at each of five different ages. A significantly higher score in stg IML started at 2 months of age, 6 weeks following seizure onset (P18, arrow), and the difference in mean staining intensity steadily increased with age. $B$, Comparison of the slopes of Timm's staining score in $+/+$ and $s t g / s t g$ mice during development. Multiple linear regression analysis indicates a significant difference $(P$ $<0.001)$ between the staining scores of the two genotypes, indicating that genotype, not age, accounts for the difference over time. $C$, Correlation between the accumulated seizure activity, calculated from the average of the seizure time (hours/day), and the staining intensity of the mossy fiber sprouting in stg mouse. Both seizure activity and staining score increase with age. There is a clear positive correlation between the burst, discharges in the immature mouse brain displayed a virtually identical pattern to that seen in the adult mutant. Data from groups of two to eight mice at different ages showing the mean incidence of cortical discharges in developing stg mice are plotted in Figure $4 B$. Within the first week of seizure onset, spontaneous discharges acquire a relatively steady rate of approximately 150 bursts/hr that is maintained at an essentially constant level during later development, since no significant changes in the mean discharge duration were found with increasing age. As a result, the overall seizure activity in stg mutants exhibits neither a dramatic increase nor decrease following the initial onset of generalized seizures.

To determine the developmental time course of mossy fiber sprouting, five groups of age-matched $+/+$ and $\mathrm{stg} / \mathrm{stg}$ mice selected to span the period pre- and postseizurc onset were assessed for mossy fiber sprouting using the selenium stain. Representative sections of the dentate gyrus from mutant temporal hippocampus at these five ages are shown in Figure 5. At P15, before seizure onset, no mossy fiber outgrowth could be detected in the IML of either control or mutant dentate gyrus. At P30, 12 d post-seizure onset, there was a barely visible but not significantly different abnormal staining pattern in the mutant. At 2 months of age, selenium staining in the stg molecular layer was uniformly more intense than in control sections. At 4 months and 6 months of age, mutants showed a progressively increasing pattern of staining intensity in the IML and granular layer. Quantitative comparisons were also performed with these staining sections. The mean Timm's staining scores of the IML/ granular layer in the midtemporal dentate gyrus in each age group $(n=4-8)$ from both genotypes are plotted in Figure $6 \mathrm{~A}$. Although dark staining in the $1 /+$ dentate molecular layer also increased slightly with age, there was a much steeper rate of increase in the mutant sections (Fig. $6 B$ ), and multiple linear regression analysis in the two genotypes indicated a significant difference in their slopes $(P<0.001)$. Figure $6 C$ summarizes the relationship between seizure activity and staining intensity of aberrant mossy fiber sprouting in the dentate during stg development. Seizure history is expressed as the accumulated seizure activity in hourly units attained by a given age, calculated from the average daily seizure time (hours/day). Seizure time is the product of the mean duration and the mean incidence of discharges per hour, and neither parameter was found to vary significantly with age in an analysis of $26 \mathrm{stg} / \mathrm{stg}$ mutants ranging in age from P18 to 6 months. The mean score of mossy fiber staining in the IML and granular layer of stg/stg mutant at different ages was used to express the extent of aberrant sprouting. As indicatcd, there is a clear positive correlation $(P<0.022)$ between the accumulated continuous seizure activity and increased mossy fiber sprouting, demonstrating that increased staining in the stg mutant is not a simple result of age.

\section{Neuronal density changes in stg hippocampus}

To determine whether the synchronous activation and mossy fiber outgrowth are accompanied by cell death, we performed area measurements and cell counts in the stg hippocampus. Using image analysis, the areas of the granule cell and CA3 pyramidal cell layers were measured bilaterally from 10-12 horizontal cresyl violet-stained sections from midtemporal hip-

$\longleftarrow$

the accumulated seizure activity and increased mossy fiber sprouting $(P$ $<0.022$ ). 
Table 2. Mean area measurements of granule and CA3 pyramidal cell layers in adult $+/+$ and $s t g / s t g$ hippocampus

\begin{tabular}{llll} 
Region & $+/+$ & stg/stg & $p$ \\
\hline Granule cell layer & $17.2 \pm 0.4$ & $18.9 \pm 1.0$ & $>0.05$ \\
CA3 pyramidal cell layer & $24.9 \pm 0.7$ & $27.7 \pm 1.8$ & $>0.05$
\end{tabular}

Mean areas of three mice are expressed as $1 \times 10^{3} \mu \mathrm{m}^{2}, \pm$ SE. Two-tailed Student's $t$ test was used.

pocampus ( $n=20-24)$ in three pairs of adult $+/+$ and $\mathrm{stg} / \mathrm{stg}$ mice. The mean area measurements from each group are compared in Table 2. A two-tailed Student's $t$ test shows no significant difference $(P>0.05)$ betwecn the two groups. The same sets of sections were used for cell counting. The mean neuronal densities of the three sampled areas in each of the three neuronal populations, including granule cells, CA3 pyramidal cells, and hilar polymorph cells, are shown in Table 3 . The neuronal densities listed in the table were all adjusted by the Abercrombie correction factor and standardized for tissue volume. These results showed no significant differences $(P>0.05)$ in the density of granule cells and CA3 pyramidal cells between the two genotypes.

In contrast, counting of individual cresyl violet-stained hilar cells revealed that this population was significantly $(P<0.05)$ reduced by $16 \%$ in the adult stg mutant compared to sections from wild-type control mice. GFAP immunocytochemistry was performed to examine the possibility that the lower total cell number in the mutant hilus might reflect selective changes in the hilar astrocyte population. Counting of matched sections revealed no significant difference in the number of GFAP-positive hilar cells in $+/+$ and $s t g / s t g$ (representing $<6.5 \%$ of the total hilar cell population), indicating that the difference in hilar cell density reflects a specific decrease in neurons rather than glia in the mutant.

In order to distinguish further whether the smaller number of hilar neurons in adult stg mutants represented a loss associated with the history of abnormal synchronous discharges or a preexisting hippocampal phenotype expressed within this particular inbred genetic background, hilar cell counts were compared in matched hippocampal sections from mutants prior to seizure onset (P17) and compared with age-matched wild-type mice $(n=2)$. At this young age, no significant differences were found between the two strains (Table 3), indicating that the reduction of hilar cells in adult stg mice represents an actual loss of cells beginning after the onset of hippocampal seizure activity.

\section{Discussion}

We have examined the innervation pattern of zinc-containing mossy fibers in the hippocampus of a mutant mouse with inherited spike-wave seizures, stargazer, and have found an increased density of ectopic Timm's staining in the IML and granular layer of the adult dentate gyrus. Electron microscopy revealed that the Timm's positive particles were localized within vesicles confined to mossy fiber synaptic terminal profiles, consistent with an aberrant outgrowth of mossy fiber axon collaterals. The ectopic mossy fiber terminals were typically seen apposed to dendritic shafts within the inner lamina of the molecular layer, confirming that the light microscopic staining pattern in this layer probably represents neosynaptogenesis. Aberrant axon sprouting followed the onset of hypersynchronous discharges within the network by a prolonged latent period of 4-6 weeks and steadily increased with age. Finally, a mild but statistically significant decrease in hilar interneuron number following seizure onset provided further evidence for a developmental reorganization of the dentate granule cell circuitry associated with chronic intermittent synchronous activation of the hippocampus by spike-wave seizures.

\section{Timm's and selenium staining methods define mossy fiber axon trajectories}

We used two complementary staining methods, Timm's sulfide silver and selenium, to trace mossy fiber axons in the stg mouse brain. Both are sensitive techniques for selectively demonstrating the distribution of zinc within vesicle-rich regions of a subpopulation of primarily glutamatergic central axons (Haug, 1973; Danscher, 1981, 1982) and both reliably delineate the mossy fiber terminal field as confirmed by comparisons with alternate methods (Represa et al., 1989; Houser et al., 1990). A particularly clear correlation of staining intensity and presynaptic terminal density is found in mossy fibers, where the precipitate responsible for the staining is located in the synaptic vesicles of the terminal boutons and in the associated synaptic clefts (Danscher and Zimmer, 1978; Danscher, 1984; PerezClausell and Danscher, 1985, 1986). In the present study, a comparison of the results using both methods in the developing mouse brain indicates that the choice of selenium may prove superior to Timm's stain, owing to a more distinct zonation pattern and higher contrast at the light microscopic level. At the ultrastructural level, however, increased sensitivity favored the Timm's stain despite technical limitations encountered in preserving cytoplasmic membrane detail.

The cellular origin of the ectopic dark-stained fibers appearing

\begin{tabular}{|c|c|c|c|}
\hline Regions & $+/+$ & stg/stg & $p$ \\
\hline \multicolumn{4}{|l|}{ Adult (5 months, $n=3$ ) } \\
\hline Granulc cclls & $489.01 \pm 12.72$ & $503.76 \pm 13.79$ & $>0.05$ \\
\hline CA3 pyramidal cells & $240.79 \pm 10.34$ & $237.85 \pm 8.46$ & $>0.05$ \\
\hline Hilar cells & $175.28 \pm 5.68$ & $152.21 \pm 5.01$ & $<0.05^{*}$ \\
\hline \multicolumn{4}{|c|}{ Immature (postnatal $17, n=2$ ) } \\
\hline Hilar cells & $156.92 \pm 2.04$ & $151.19 \pm 2.40$ & $>0.05$ \\
\hline
\end{tabular}

Mean densities are expressed as neurons per sample region $\left(1 \times 10^{6} \mu \mathrm{m}^{3}\right), \pm$ SE. Two tailed Student's $t$ test was used.

* Statistically different from control data. 
in the IML of the dentate has been considered for some time. Early Golgi studies of rat hippocampus describe a small population of axons in the mossy fiber hilar plexus giving off recurrent collaterals that pass through the granular layer and reach into the molecular layer (Ramon y Cajal, 1911; Lorente de No, 1934). The Timm's method applied to adult wild-type mouse brain also shows very sparse, dark mossy fiber terminal-like staining in both the granular layer and the adjacent IML, probably representing a small population of recurrent axon collaterals branching from parent mossy fibers within the hilus. The increased staining in the molecular layer following hippocampal lesions is therefore generally assumed to represent de novo proliferation of this recurrent axon arbor, but the potential for accumulation of historeactive zinc in other elements of the neuropil or in the associated synaptic clefts cannot be excluded. Several lines of evidence, however, support the idea that the aberrant staining patterns in the IML do, in fact, represent mossy fiber collaterals. First, using the Golgi-electron microscopic technique, aberrant mossy fibers have been identified in the IML of the deafferented rat hippocampus terminating on granule cell dendrites (Frotscher and Zimmer, 1983). Second, opiates coexist with zinc in mossy fibers, and dynorphin immunocytochemistry has revealed a staining pattern fully coincident with that of the Timm's stain in the dentate IML in human epilepsy surgical specimens (Houser et al., 1990).

We made additional attempts to visualize mossy fiber reorganization directly in the stg mutant by labeling the mossy fiber system extracellularly with a dicarbocyanine dye (DiI). DiI revealed a sharp band of ectopic fluorescence in the IML of dentate gyrus consistent with the Timm's and selenium staining pattern (X. Qiao and J. L. Noebels, unpublished observations). The precise identity of these Dil-positive fibers remained ambiguous, however, even when traced individually from the hilar region to the IML, since the parent cell somata were not visible in the $40 \mu \mathrm{m}$ section plane, and the possibility of colabeling other afferent processes projecting into the IML, such as axon collaterals from hilar mossy cells (Ribak et al., 1985) could not be excluded. In parallel studies using thick $(450 \mu \mathrm{m})$ sections, intracellular injections of neurobiotin into single $\mathrm{stg} / \mathrm{stg}$ dentate granule neurons revealed a marked increase in mossy fiber branching complexity within the hilus compared with $+/+$ sections (L. Rihn and J. L. Noebels, unpublished results), compatible with interstitial axon budding (O'Leary and Terashima, 1988). Although no collaterals could be traced anterogradely into the IML, these fibers have recently been visualized in human epileptic hippocampus (Isokawa et al., 1993).

The second approach used in our study was Timm's stain electron microscopy. Although the method has been widely used for light microscopic localization of heavy metals in biological tissues and selectively stains zinc-filled vesicles in mossy fiber boutons, standard protocols for glutaraldehyde fixation and osmification interfere with the sulfide silver staining process and limit optimal preservation of membrane detail at the electron microscopic level (Danscher and Zimmer, 1978; Danscher, 1981; Frederickson and Danscher, 1990). Using the normal ultrastructure of mossy fibers in the rodent dentate gyrus as a guide (Amaral and Dent, 1981; Claiborne et al., 1986), we focused on localization of the reaction product in the molecular and granule cell body layers. As shown in Figure 3, the finding of Timmpositive particles in neurotransmitter vesicles intermixed with mitochondria in the $1 \mathrm{ML}$ and granular layers of the mutant provides the best available evidence that the dark-staining band of precipitate seen by light microscopy represents presynaptic mossy fiber terminals.

\section{Mossy fiber sprouting and hilar interneuron loss are linked to spike-wave seizures}

In a previous study, Stanfield (1989) reported trace levels of ectopic Timm's stain in the IML of the adult tottering $(\mathrm{tg})$ mouse, a genetically unrelated (Chr 8$)$ recessive mutant that shares a similar (6 spikes/sec) but far less severe epileptic phenotype than the stg mutant (Noebels and Sidman, 1979; Qiao and Noebels, 1991), and we have confirmed this finding using the Timm's stain in adult $\mathrm{tg} / \mathrm{tg}$ mice (data not shown). The striking increase in sprouting in stg mice corresponds to the twofold greater spontaneous discharge rate and duration in the stg mutant, where seizures comprise roughly $20 \%$ of total waking EEG activity. In Stanfield's study there was no evidence of sprouting in immature (P17) $\mathrm{tg} / \mathrm{tg}$ mutants; however, it remained unclear from that observation whether the sprouting phenotype represented a secondary result of the seizures, a polymorphism in the background strain, or an unrelated action of the $t g$ mutant gene.

Our findings in the stargazer mutation, a mouse mutant that shares the spike-wave discharges as a common phenotype, extend this result to provide additional evidence that mossy fiber sprouting is seizure- rather than gene-linked. In both mutants, seizures predate the onset of sprouting. The serial study in developing $\mathrm{stg} / \mathrm{stg}$ homozygotes reveals a steady correlation between accumulated spike-wave seizure activity and the degree of abnormal mossy fiber sprouting. The two mutations are on different inbred genetic backgrounds. Finally, the pattern of intervening cellular defects underlying epileptogenesis in stg and $t g$ are now known to be heterogeneous (Qiao and Noebels, 1991). Taken together, the results from both mutants demonstrate that mossy fiber sprouting is unlikely to be a primary effect of either mutant gene or background genotype, but is rather a shared secondary consequence of the prolonged history of synchronous spike-wave activation. Further evaluation of the intensity of mossy fiber sprouting in these mutants following pharmacological blockade of seizures beginning early in development would provide an important additional test of this hypothesis.

\section{Hippocampal sprouting follows seizure onset with a significant developmental delay}

An unexpected finding in the present study is that the developmental onset of mossy fiber sprouting follows the appearance of spike-wave seizures in the stg mutant by a period of 4-6 weeks. This latency is significant from two points of view. First, it provides a clear indication that the sprouting process is not necessary for the generation of spontaneous spike-wave activity within the hippocampus, and is therefore consistent with substantial evidence suggesting that the spike-wave pattern of generalized synchronization is generated primarily in thalamus and neocortex (Jasper and Droogleever-Fortuyn, 1946; Fisher and Prince, 1977; Gloor, 1984), with subsequent activation of other synaptically linked brain regions. In the stg model, hippocampal circuits serve as secondary targets for the spread of $6 / \mathrm{sec}$ thalamocortical discharges, presumably through efferent pathways from entorhinal cortex and the thalamic nucleus reuniens (Wouterlood et al., 1990). Second, the delayed onset of sprouting in $s t g$ provides important additional insight into the underlying mechanisms mediating pathological neurite outgrowth (discussed below). 


\section{Mechanisms underlying mossy fiber reorganization}

The mechanisms proposed to mediate axon terminal growth and rearrangement can be divided into three major categories: first, a presynaptic process solely dependent on alterations in intrinsic neural excitability and impulse activity; second, a process initiated primarily by postsynaptic signals (e.g., deafferentation induced); and third, a nonsynaptic process mediated by local neuronal cell death with associated glial activation. Each of these factors, alone or in combination, might trigger pathological axon elongation and neosynaptogenesis.

(1) Increased impulse activity. The clearest examples of increased presynaptic activity leading to terminal outgrowth have been shown in the PNS. In Drosophila, the inherited pattern of hyperactivity induced by the genetic deletion of functional A-type potassium channels in the Shaker mutant induces excess branching of the motoneuron axon terminal projection, leading to a striking pattern of muscle fiber hyperinnervation (Budnik et al., 1990). At the crayfish neuromuscular junction, chronic stimulation of phasic motoneurons also raises the number of synapses formed at the terminal end-plate (Lnenicka et al., 1986). These studies suggest that hyperactivity in presynaptic elements, possibly when synchronized with postsynaptic depolarization, provides a sufficient stimulus for terminal growth in the absence of denervation or local cell injury.

(2) Local cell death. In the mammalian CNS, most experimental lesions that lead to chronic hyperexcitability and axon sprouting are also accompanied by extensive cell death, deafferentation, and gliosis. In the best-studied example, loss of hilar interneurons and pyramidal neurons in the hippocampal CA3 region is seen along with mossy fiber reorganization following lesions induced by kainic acid or focal electrical stimulation (Cotman and Nadler, 1978). A similar complex pattcrn of pathological axon rearrangement is also present in surgical specimens from patients with temporal lobe epilepsy (DeLanerolle et al., 1989; Sutula et al., 1989; Babb et al., 1991), where the extent of aberrant sprouting appears related to the amount of cell loss in the polymorph and CA3 fields (Houser et al., 1990). More recently, the progressive decrease in interneuron density within the hilar polymorphic region of the dentate gyrus found during kindling has been proposed as a possible mechanism underlying mossy fiber synaptic reorganization (Cavazos and Sutula, 1990).

Our findings in the stargazer mutant are consistent with either of these general mechanisms, but help to delineate the necessary and sufficient conditions for mossy fiber sprouting with further precision. First, we found no evidence of dentate granule cell or hippocampal pyramidal cell loss, and can therefore conclude that damage to granule cells themselves or in their primary postsynaptic target population is not specifically required for pathological mossy fiber outgrowth. A corollary of this observation is that the loss of a secondary collateral postsynaptic target (i.e., the hilar interneurons) may alone be sufficient to initiate expansion of the remaining axonal arbor. Second, the relatively mild degree of hilar neuron loss found in the advanced stage of sprouting in the adult stg mutant (15\%) is quantitatively less significant than that described in other models (40-80\%) with a comparable intensity of sprouting, and thus the amount of reorganization appears to correlate better with the absolute amount of seizure activity than with the degree of regional cell loss in the hippocampus (Cavazos and Sutula, 1990). Hilar cells are among the most vulnerable population for excitotoxic cell death in the hippocampus, and the loss of these inhibitory in- terneurons are functionally significant in regulating excitability in this circuit, since they not only exert feedforward inhibition of pyramidal cells, but also feedback inhibition of granule cells. Loss of these inhibitory synapses also creates postsynaptic vacancies on granule cell dendrites, an additional requirement for reinnervation by aberrant mossy fiber collaterals. Finally, sprouting in other models of focal hippocampal epilepsy is associated with sustained depolarizations that upregulate the expression of glial as well as neuronal genes (Steward et al., 1991); it is plausible that reactive changes in astrocytes could subsequently trigger the initial steps in axon proliferation as a generic response to regional metabolic injury. In the nonconvulsive model of spike-wave hypersynchrony studied here, however, we found no evidence for abnormal numbers of hippocampal astrocytes or reactive increases in GFAP, an inducible marker of glial activation. The absence of an obvious glial reaction in the stg model therefore suggests that the gliosis present in other models is unlikely to play a critical role in stimulating granule cell axon collateral outgrowth.

(3) Sprouting follows early seizures with a significant developmental delay. Age dependence is another factor related to mossy fiber outgrowth in the stg dentate molecular layer. In normal rat development, most granule cells $(85 \%)$ are formed postnatally in the hilus and cell proliferation is complete by 3 weeks after birth (Bayer and Altman, 1975; Bayer, 1980a,b). Although the first mossy fibers reach the distal part of the regio inferior on P1 (Gaarskjaer, 1985), and a well-defined mossy fiber trajectory in the lateral hilus and adjacent suprapyramidal portion of the proximal regio inferior can be traced by Timm's stain at birth, the mossy fiber projection continues to mature throughout early postnatal development. By P24 in the rat, all zones of the granule layer contain cells that project distally (Zimmor and Haug, 1978; Amaral and Dent, 1981), and there is a remarkable similarity in the organization of the mossy fiber system across a wide range of mammalian species (Gaarskjaer, 1986).

We found a 4-6 week delay between the onset of spike-wave discharges in the immature $\mathrm{stg} / \mathrm{stg}$ mutant mouse and significant levels of mossy fiber sprouting. This latency is consistent with evidence from kainic acid-lesioned rats that the immature brain may be less susceptible to seizure-induced brain damage (Nitecka et al., 1984) and sprouting during the first few postnatal weeks (Sperber et al., 1991), since signs of mossy fiber sprouting into the IML can be detected after only $4 \mathrm{~d}$ of kindling stimulation in the adult (Cavazos et al., 1991).

One possible mechanism underlying this resistance to activity-stimulated growth in the immature brain may be reflected in the age dependence of trophic factor gene expression. Growth factors facilitate axon regeneration in the adult hippocampus (Represa et al., 1987; Gage et al., 1990), and gene expression for several neurotrophic factors is upregulated by epileptiform discharges (Gall and Isackson, 1989; Ernfors et al., 1991; Isackson et al., 1991; Dugich-Djordjevic et al., 1992a). Recently, however, a clear dissociation between seizure activity and upregulation of brain-derived neurotrophic factor $m$ RNA expression has been identified in immature brain (Dugich-Djordjevic et al., $1992 \mathrm{~b}$ ), suggesting that the induction of gene expression for a specific growth factor may not yet be coupled to electrical activity. On the other hand, when dentate granule cells are partially deafferented by perforant path lesions, mossy fiber collateral sprouting appears in both immature (1-30 d old) and adult rats during the second or third week postlesion, with the earliest 
sprouting starting within 4-7 d postlesion (I aurberg and 7immer, 1981); commissural fiber sprouting on granule cell dendrites also shows a more vigorous response in immature animals (Gall and Lynch, 1978). One of the possible explanations for this discrepancy could be that the identity or intensity of growth signals triggered by deafferentation are different from those evoked in the kindling and inherited spike-wave models.

Studies in the kindling model confirm the possibility that the intensity of the synchronous discharge may be an additional determinant of the prolonged latency for the appearance of mossy fiber sprouting following spike-wave seizure onset. Twice-daily low-frequency perforant path stimulation (62 constant-current biphasic pulses of $1.0 \mathrm{msec}$ duration at $0.2 \mathrm{~Hz}$ ) induces supragranular mossy fiber staining in $15 \mathrm{~d}$, while twice-daily highfrcquency kindling stimulation ( $1 \mathrm{scc}$ train of $62 \mathrm{~Hz}$ biphasic 1 msec pulses) requires only 5-6 d to produce visible synaptic reorganization (Sutula et al., 1988). This dose effect could underlie the steady increase in sprouting with continued seizure history in stg mice, and would explain the quantitative difference in sprouting intensities between the low-seizure-rate $(t g)$ and the high-seizure-rate (stg) mutants.

A further aspect of age dependence is shown in our developmental control group. In $+/+$ mice, we found a small number of ectopic mossy fiber terminals extending into the IML of the temporal hippocampus that appeared gradually with increasing age. Similar age-dependent changes in the distribution of mossy fiber collaterals have been reported in unaffected rats (Gaarskjaer, 1978) and in humans (Cassell and Brown, 1984). Thus, the sprouting phenomenon may represent a process occurring during normal aging that slowly integrates the history of patterned synchronous activity and hilar interneuron loss in hippocampal pathways.

\section{Physiological significance of synaptic reorganization in $\mathrm{stg}$ hippocampus}

An important question arising from the data on pathological axon sprouting described in both human and experimental models of hippocampal seizures is whether the sprouting functionally alters granule cell network behavior, either by serving as the primary anatomical substrate for epileptogenesis, or by interfering with other aspects of information processing in the circuit. Zinc alters signaling at NMDA and GABAergic synapses (Westbrook and Mayer, 1987), and enhanced recurrent excitation caused by mossy fiber sprouting could increase the excitatory glutamatergic output from granule cells, while excess zinc release might simultaneously induce giant depolarizing synaptic potentials in CA3 cells by inhibitory actions on pre- and postsynaptic $\mathrm{GABA}_{\mathrm{B}}$ receptors (Xie and Smart, 1991). Electrophysiological evidence in the kainic acid model suggests that mossy fiber axon collaterals form a functional recurrent excitatory circuit that could favor seizure expression, particularly with coexisting disinhibition (Tauck and Nadler, 1985; Cronin et al., 1992). A correlation between mossy fiber synaptic reorganization and the development, progression, and permanence of the kindling phenomenon has also been shown in the rat (Cavazos et al., 1991). It remains difficult, however, to assess the selective contribution of mossy fiber sprouting to epileptogenesis in each of these chronic lesions, since the outgrowth progresses in tandem with synaptic disinhibition and other intrinsic membrane excitability changes (Mody et al., 1990).

In the stg mutant, preliminary in vilro experiments in sprouled stg hippocampal slices reveal alterations in potassium-induced
CA3 pyramidal neuron network bursting compared to $+/+$ slices (Namgung and Noebels, 1991), and excess zinc release is a candidate mechanism for this defect. However, we have found no in vivo evidence of spontaneous focal hippocampal seizures, even in 8-month-old mice. While the excitability thresholds to convulsants applied in vivo have not yet been examined, these data suggest that circuit alterations triggered by the sprouting process with only mild hilar interneuron loss do alter network signaling in the stg lesion, but are insufficient to cause the spontaneous appearance of focal hippocampal epilepsy.

A major implication of the findings in the present study is that spike-wave epilepsy may increase the risk for activity-dependent pathological brain development in patients with this seizure pattern, and that a prolonged history of generalized hypersynchronous discharges, like other more severe patterns of convulsive seizure activity, may slowly induce cell death in vulnerable neurons. Depth EEG studies in man have established that hippocampal spike-wave activity can accompany thalamocortical synchronization in generalized absence epilepsy, and have reported $3 / \mathrm{sec}$ spike-wave bursts in orbitofrontal cortex, cingulate gyrus, hippocampus, and amygdala, indicating that most synaptically linked structures within the limbic circuit as well as the thalamus, subthalamus, and basal ganglia are involved along with the neocortical discharge (Williams, 1953; Angeleri et al., 1964; Niedermeyer et al., 1969). Bursts of generalized spike-waves can occur hundreds of times per day (Browne et al., 1983) at frequencies ranging from 2.5 to $10 \mathrm{~Hz}$, and constitute the predominant EEG abnormality in a large number of childhood epilepsy syndromes with diverse etiologies and outcomes (Aicardi, 1986). Anatomical reorganization of the mossy fiber terminals and other synchronized extrahippocampal pathways, if present clinically, also suggests a potential mechanism for secondary epileptogenesis in the $40-50 \%$ of patients with generalized absence epilepsy who later develop associated convulsive seizure patterns.

\section{References}

Abercrombie M (1946) Estimation of nuclear population from microtome sections. Anat Rec 94:239-247.

Aicardi J (1986) Epilepsy in children. New York: Raven.

Amaral DG, Dent JA (1981) Development of the mossy fibers of the dentate gyrus. I. A light and electron microscopic study of the mossy fibers and their expansions. J Comp Neurol 195:51-86.

Angeleri F, Ferro-Milone F, Parigi S (1964) Electrical activity and reactivity of the rhinencephalic, pararhinencephalic and thalamic structures: prolonged implantation of elcctrodes in man. Elcctrocncephalogr Clin Neurophysiol 16:100-129.

Archer SM, Dubin MW, Stark LA (1982) Abnormal development of kitten retino-geniculate connectivity in the absence of action potentials. Science 217:743-745.

Babb TL, Kupfer WR, Pretorius JK, Crandall PH, Levesque MF (1991) Synaptic reorganization by mossy fibers in human epileptic fascia dentata. Neuroscience 42:351-363.

Baumbach HD, Chow KL (1981) Visuocortical epileptiform discharges in rabbits: differential effects on neuronal development in the lateral geniculate nucleus and superior colliculus. Brain Res 209:61-76.

Bayer SA (1980a) Development of the hippocampal region in the rat. I. Neurogenesis examined with ${ }^{3} \mathrm{H}$-thymidine. J Comp Neurol 190: 87-114.

Bayer SA (1980b) Development of the hippocampal rcgion in the rat. II. Morphogenesis during embryonic and early postnatal life. J Comp Neurol 190:115-134.

Bayer SA, Altman J (1975) The effects of x-irradiation on the postnatally-forming granule cell population in the olfactory bulb, hippocampus and cerebellum of the rat. Exp Neurol 48:167-174.

Beltz BS, Burd GD (1989) Immunocytochemical techniques: principles and practice. Oxford: Blackwell. 
Browne TR, Dreifuss FE, Penry JK, Porter RJ, White BJ (1983) Clinical and EEG estimates of absence seizure frequency. Arch Neurol 40:469-472.

Budnik V, Zhong Y, Wu C-F (1990) Morphological plasticity of motor axons in Drosophila mutants with altered excitability. J Neurosci 10: 3754-3768.

Cassell MD, Brown MW (1984) The distribution of Timm's stain in the nonsulphide-perfused human hippocampal formation. J Comp Neurol 222:461-471.

Cavazos JE, Sutula TP (1990) Progressive neuronal loss induced by kindling: a possible mechanism for mossy fiber synaptic reorganization and hippocampal sclerosis. Brain Res 527:1-6.

Cavazos JE, Goliarai G, Sutula TP (1991) Mossy fiber synaptic reorganization induced by kindling: time course of development, progression, and permanence. J Neurosci 11:2795-2803.

Chow KL, Baumbach HD, Glanzman DL (1978) Abnormal development of lateral geniculate neurons in rabbit subjected to either eyelid closure or corticofugal paroxysmal discharges. Brain Res 146: 151-158.

Claiborne BJ, Amaral DG, Cowan WM (1986) A light and electron microscopic analysis of the mossy fibers of the rat dentate gyrus. $J$ Comp Neurol 246:435-458.

Constantine-Paton M, Cline HT, Debski E (1990) Patterned activity, synaptic convergence, and the NMDA receptor in developing visual pathways. Annu Rev Neurosci 13:129-154.

Cotman CW, Nadler JV (1978) Reactive synaptogenesis in the hippocampus. In: Neuronal plasticity (Cotman CW, ed), pp 227-271. New York: Raven.

Cronin J, Obenaus A, Houser CR, Dudek FE (1992) Electrophysiology of dentate granule cells after kainate-induced synaptic reorganization of the mossy fibers. Brain Res 573:305-310.

Danscher G (1981) Histochemical demonstration of heavy metals. A revised version of the sulfide silver method suitable for both light and electron microscopy. Histochemistry 71:1-16.

Danscher G (1982) Exogenous selenium in the brain. A histochemical technique for light and electron microscopical localization of catalytic selenium bonds. Histochemistry 76:281-293.

Danscher G (1984) Dynamic changes in the stainability of rat hippocampal mossy fiber boutons after local injection of sodium sulfide, sodium selenite, and sodium diethyldithiocarbamate. In: The Neurobiology of zinc, Vol B (Frederickson CD, Kasarskis EJ, Howell GA, eds), pp 177-191. New York: Liss.

Danscher G, Zimmer J (1978) An improved Timm's sulfide silver method for light and electron microscopic localization of heavy metals in biological tissues. Histochemistry 55:27-40.

DeLanerolle NC, Kim JH, Robbins RJ, Spencer DD (1989) Hippocampal interneuron loss and plasticity in human temporal lobe epilepsy. Brain Res 495:387-395.

Dugich-Djordjevic MM, Lapchack PA, Tocco G, Pasinetti G, Baudry $M$, Hefti F (1992a) Regionally specific and rapid increases in BDNF mRNA in the adult rat brain following seizures induced by systemic administration of kainic acid. Neuroscience 47:303-315.

Dugich-Djordjevic MM, Tocco G, Willoughby DA, Najm I, Pasinetti G, Thompson RF, Baudry M, Lapchack PA, Hefti F (1992b) BDNF mRNA expression in the developing rat brain following kainic acidinduced seizure activity. Neuron 8:1127-1138.

Ernfors P, Bengzon J, Kokaia Z, Persson H, Lindvall O (1991) Increased levels of messenger RNAs for neurotrophic factors in the brain during kindling epileptogenesis. Neuron 7:165-176.

Fisher RS, Prince DA (1977) Spike-wave rhythms in cat cortex induced by parental penicillin. I. Electroencephalographic features. Electroencephalogr Clin Neurophysiol 42:608-624.

Frederickson CJ, Danscher G (1990) Zinc containing neurons in CNS. Prog Brain Res 83:71-84.

Frotscher M, Zimmer J (1983) Lesion-induced mossy fibers to the molecular layer of the rat facia dentata: identification of postsynaptic granule cells by the Golgi-EM technique. J Comp Neurol 215:299311.

Gaarskjaer FB (1978) Organization of the mossy fiber system of the rat studied in extended hippocampi. I. Terminal area related to number of granule and pyramidal cells. J Comp Neurol 178:49-72.

Gaarskjaer FB (1985) The development of the dentate area and the hippocampal mossy fiber projection of the rat. J Comp Neurol 241: $154-170$.
Gaarskjaer FB (1986) The organization and development of the hippocampal mossy fiber system. Brain Res Rev 11:335-357.

Gage FH, Buzsaki G, Armstrong DM (1990) NGF-dependent sprouting and regeneration in the hippocampus. Prog Brain Res 83:357370 .

Gall CM, Isackson PJ (1989) Limbic seizures increase neuronal production of messenger RNA for nerve growth factor. Science 245:758761.

Gall CM, Lynch G (1978) Rapid axon sprouting in the neonatal rat hippocampus. Brain Res 53:357-362.

Gloor P (1984) Electrophysiology of generalized epilepsy. In: Electrophysiology of epilepsy (Schwartzkroin PA, Wheal H, eds), pp 107136. London: Academic.

Haug F-MS (1973) Heavy metals in the brain: a light microscope study of the rat with Timm's sulfide silver method, methodological considerations and cytological and regional staining patterns. Adv Anat Embryol Cell Biol 47:1-71.

Houser CR, Miyashiro JE, Swartz BE, Walsh GO, Rich JR, DelgadoEscueta AV (1990) Altered patterns of dynorphin immunoreactivity suggest mossy fiber reorganization in human hippocampal epilepsy. J Neurosci 10:267-282.

Hubel DH, Wiesel TN (1965) Binocular interaction in striate cortex of kittens reared with artificial squint. J Neurophysiol 28:1041-1059.

Isackson PJ, Huntsman MM, Murray KD, Gall CM (1991) BDNF mRNA expression is increased in adult rat forebrain after limbic seizures: temporal patterns of induction distinct from NGF. Neuron 6:937-948.

Isokawa M, Levesque MF, Babb TL, Engel J Jr (1993) Single mossy fiber axonal systems of human dentate granule cells studied in hippocampal slices from patients with temporal lobe epilepsy. J Neurosci 13:1511-1522.

Jasper H, Droogleever-Fortuyn J (1946) Experimental studies on the functional anatomy of petit mal. Res Publ Assoc Res Nerv Ment Dis 26:272-298.

Laurberg S, Zimmer J (1981) Lesion-induced sprouting of hippocampal mossy fiber collaterals to the fascia dentata in developing and adult rats. J Comp Neurol 200:433-459.

Lnenicka GA, Atwood HL, Marin L (1986) Morphological transformation of synaptic terminals of a phasic motoneuron by long-term tonic stimulation. J Neurosci 6:2252-2258.

Lorente de No R (1934) Studies on the structure of the cerebral cortex. II. Continuation of the study of the Ammonic system. J Psychol Neurol 46:113-177.

Lynch G, Deadwyler S, Cotman CW (1973) Post lesion axonal growth produces permanent functional connections. Science 180:1364-1366.

Mastronarde DN (1983) Correlated firing of cat retinal ganglion cells. I. Spontaneously active inputs to X-and Y-cells. J Neurophysiol 49: 303-324.

Merzenich MM, Kaas JH, Wall JT, Sur M, Nelson RJ, Felleman DJ (1983) Progression of change following median nerve section in the cortical representation of the hand in areas $3 b$ and 1 in adult owl and squirrel monkeys. Neuroscience 10:639-665.

Mody I, Reynolds JN, Salter MW, Carlen PL, McDonald JF (1990) Kindling induced epilepsy alters calcium currents in granule celis of rat hippocampal slices. Brain Res 531:88-94.

Nadler JV, Perry BW, Cotman CW (1980) Selective reinnervation of hippocampal area $\mathrm{CA} 1$ and the facia dentata after destruction of CA3CA4 afferents with kainic acid. Brain Res 182:1-9.

Namgung U, Noebels JL (1991) Hippocampal CA3 pyramidal cells of the epileptic mutant mouse stargazer display a distinctive genelinked hyperexcitability. Soc Neurosci Abstr 17:170.

Niedermeyer E, Laws ER, Walker AE (1969) Dcpth EEG findings in epileptics with generalized spike-wave complexes. Arch Neurol 21: $51-58$.

Nitecka L, Tremblay E, Charton G, Bouillot JP, Berger ML, Ben-Ari Y (1984) Maturation of kainic acid seizure-brain damage syndrome in the rat. II. Histopathological sequelae. Neuroscience 13:1073-1094.

Noebels JL, Sidman RL (1979) Inherited epilepsy: spike-wave and focal motor seizures in the mutant mouse tottering. Science 204:13341336.

Noebels JL, Qiao X, Bronson RT, Spencer C, Davisson MT (1990) Stargazer: a new neurological mutant on chromosome 15 in the mouse with prolonged cortical seizures. Epilepsy Res 7:129-135.

O'Leary DDM, Terashima T (1988) Cortical axons branch to multiple 
subcortical targets by interstitial axon budding: implications for target recognition and 'waiting periods.' Neuron 1:901-910.

Perez-Clausell J, Danscher G (1985) Intravesicular localization of zinc in rat tclencephalic boutons. Brain Res 337:91-98.

Perez-Clausell J, Danscher G (1986) Release of zinc sulfide accumulations into synaptic clefts after in vivo injection of sodium sulfide. Brain Res 362:358-361.

Qiao X, Noebels JL (1991) Genetic and phenotypic heterogeneity of inherited spike-wave epilepsy: two mutant gene loci with independent cerebral excitability. Brain Res 555:43-50.

Ramon y Cajal S (1911) Histologie du system nerveux de l'homme et des vertebres, Vol II. Paris: Maloine.

Represa A, Tremblay E, Ben-Ari Y (1987) Aberrant growth of mossy fibers and enhanced kainic acid binding sites induced in rats by early hyperthyroidism. Brain Res 423:325-328.

Represa A, Robain O, Tremblay E, Ben-Ari Y (1989) Hippocampa plasticity in childhood epilepsy. Neurosci Lett 99:351-355.

Ribak CE, Scress L, Amaral DG (1985) The development, ultrastructure and synaptic connections of the mossy cells of the dentate gyrus J Neurocytol 14:835-857.

Shatz CJ (1990) Impulse activity and the patterning of connections during CNS development. Neuron 5:745-756.

Shatz CJ, Stryker MP (1988) Prenatal tetrodotoxin infusion blocks segregation of retinogeniculate afferents. Science 242:87-89.

Shaw C, Cynader M (1984) Disruption of cortical activity prevents ocular dominance changes in monocularly deprived kittens. Nature 308:731-734.

Sidman RL, Angevine JB Jr, Pierce ET (1971) Atlas of the mouse brain and spinal cord. Cambridge, MA: Harvard UP.

Slotnick BM, Leonard CM (1975) A stereotaxic atlas of the albino mouse forebrain. Rockville, MD.

Spcrber EF, Haas KZ, Stanton PK, Moshe SL (1991) Resistance of the immature hippocampus to seizure-induced synaptic reorganization. Dev Brain Res 60:88-93.

Sretavan DW, Shatz CJ (1986) Prenatal development of retinal ganglion cell axons: segregation into eye-specific layers. J Neurosci 6:234251.

Stanfield BB (1989) Excessive intra- and supragranular mossy fibers in the dentate gyrus of tottering $(\mathrm{tg} / \mathrm{tg})$ mice. Brain Res 480:294-299.
Steriade M, Jones EG, Llinas RR (1990) Thalamic oscillations and signaling. New York: Wiley.

Steward O, Torre ER, Tomasulo R, Lothman E (1991) Neuronal activity upregulates astroglial gene expression. Proc Natl Acad Sci USA 88:6819-6823.

Stryker MP, Harris WA (1986) Binocular impulse blockade prevents the formation of ocular dominance columns in cat visual cortex. $J$ Neurosci 6:2117-2133.

Sutula T, He XX, Cavazos J, Scott G (1988) Synaptic reorganization in the hippocampus induced by abnormal functional activity. Science 239:1147-1150.

Sutula T, Cascino G, Cavazos J, Parada I, Ramirez L (1989) Mossy fiber synaptic reorganization in the epileptic human temporal lobe. Ann Neurol 26:321-330.

Tauck DL, Nadler JV (1985) Evidence of functional mossy fiber sprouting in hippocampal formation of kainic acid-treated rats. $J$ Neurosci 5:1016-1022.

Westbrook GL, Mayer ML (1987) Micromolar concentrations of $\mathrm{Zn}^{2+}$ antagonize NMDA and GABA responses of hippocampal neurons. Nature 328:640-643.

Wiesel TN, Hubel DH (1963) Comparison of the effects of unilateral and bilateral eye closure on cortical unit responses in kittens. J Neurophysiol 26:1003-1017.

Williams D (1953) A study of thalamic and cortical rhythms in "petit mal." Brain 76:50-69.

Wouterlood FG, Saldana E, Witter MP (1990) Projection from the nucleus reuniens thalami to the hippocampal region: light and electron microscopic tracing study in the rat with the anterograde tracer Phaseolus vulgaris-leucoagglutinin. J Comp Neurol 296:179-203.

Xie X, Smart TG (1991) A physiological role for endogenous zinc in rat hippocampal synaptic neurotransmission. Nature 349:521-524.

Zimmer J (1974) Long-term synaptic reorganization in rat facia dentata deafferented at adolescent and adult stages: observations with the Timm's method. Brain Res 76:336-342.

Zimmer J, Haug FM (1978) Laminar differentiation of the hippocampus, fascia dentata and subiculum in developing rats, observed with the Timm's sulphide silver method. J Comp Neurol 179:581-618. 